\title{
INJUSTIÇA E BANALIDADE DO MAL EM HANNAH ARENDT
}

\author{
Injustice and banality of evil in Hannah Arendt
}

Odílio Alves Aguiar

UFC

\begin{abstract}
Resumo: Na ausência de uma teoria explícita da justiça, em Arendt, iremos abordar o assunto através de um. desvio: tomaremos os campos de concentração como ponto de partida; abordaremos os conceitos de mal radical e banalidade do mal; e mostraremos que, nessa autora, o antídoto para a injustiça reside na concepção de justiça significando julgamento e não ao modo pensado pela tradição: virtude e valor. Essa discussão se dá dentro da tentativa arendtiana de recuperar o sentido originário da política, o mundo comum, esteio da condição humana na qual a diversidade e a pluralidade são requisitos para novos começos, novas instituições, novos atos de liberdade. Utilizaremos, prioritariamente, para balizar a nossa reflexão, além da obra de Hannah Arendt, os livros Justiça em tempos sombrios, de Cristina Ribas (2005) e Hannah Arendt e a banalidade do mal, de Nádia Souki (1998).
\end{abstract}

Palavras chave: Justiça, injustiça, mal radical, mal banal, julgamento.

\begin{abstract}
In the absence of an explicit theory of justice, in Arendt, we will work on the subject through a detour: we will take the concentration camps as a starting point; we will approach the concepts of radical evil and banality of evil and show that in Arendt the antidote to injustice lies in the concept of justice as judgment and not as value and virtue as tradition has thought. This discussion takes place within the arendtian attempt to recover the original meaning of politics, the common world, the mainstay of the human condition in which diversity and plurality are requirements for new beginnings, new institutions, new acts of freedom. We will use, primarily, as a mark of our reflection, besides the work of Hannah Arendt, the books Justice in Dark Times, by Cristina Ribas (2005) and Hannah Arendt and Banality of Evil, by Nádia Souki (1998).
\end{abstract}

Keywords: Justice, injustice, radical evil, banal evil, judgment.

De início, podemos afirmar que não há uma teoria da justiça em Hannah Arendt e o tema da injustiça não constitui um topos explícito da reflexão e da argumentação da autora. Não encontramos nos seus escritos argumentos elaborados a partir de um sistema discursivo guiado pela ideia de justiça, mas a falta desse tipo de discurso não inviabiliza uma reflexão sobre o assunto na pensadora, antes constitui um desafio. Arendt distanciou-se dessa semântica em razão da retórica comunista ter-se apropriado hegemonicamente desse topos, assim como distanciou-se do lugar comum da tolerância em razão da lhegemonia do discurso liberal na apropriação desse assunto. Da ideologia comunista e liberal, ela fazia questão de distanciar-se.

Apesar de não usar da retórica da justiça/injustiça, por um desvio e indícios, podemos captar, no seu pensamento ético-político, várias possibilidades heurísticas capazes de iluminar o tema em pauta. É possível perceber que essas questões não passaram em branco em Hannah Arendt. Suas reflexões podlem dar contribuições valiosas ao assunto, pois marcadas pela maior injustiça que os seres humanos podem passar: a condenação ao extermínio, à eliminação e ao desterro sem imputação de culpa ou crime. Isto é, pensar o tema em pauta, nessa autora, é pensar a vida em tempos sombrios. A reflexão sobre a injustiça, reunível nos seus escritos, nasce da experiência 
dos campos de concentração. Trata-se de uma experiência radicalmente nova completamente diferente de qualquer tirania, ditadura, escravidão ou exploração do homem pelo homem. Esse acontecimento gerou, por causa da sua novidade, uma ruptura, levando Arendt a dizer, seguindo Tocqueville: desde que o passado deixou de lançar sua luz sobre o futuro, a mente do homem vagueia nas trevas. Os campos de concentração colocam em cena o genocídio, naquele momento, um tipo de crime sem nenhuma tipificação nos códigos do direito, na literatura ética ou na filosofia política. Trata-se, pela primeira vez na história do Ocidente, da instauração de uma forma de governo erguida em contraposição ao próprio gênero humano.

O campo de concentração como experiência tipificadora do governo totalitário ultrapassa, assim, o preconceito, a perseguição a um agrupamento humano específico ou a expropriação territorial. Não se tratava mais, evidentemente, de um preconceito social ou religioso, de seleção de companhia, mas de uma política de Estado e foi justamente isso que os judeus não entenderam. Presos à mentalidade da nação escolhida, da perseguição religiosa ou ao assimilacionismo social, os judeus não perceberam que estavam diante de algo muito diferente e não apenas de proporções maiores. A noção de Holocausto e de sacrifício não dão conta da novidade desse acontecimento. Uma nova forma de governo, com ambição de dominação total, estava surgindo estribado na proposta de purificação, extinção de raças e de setores da população. Diante dessa proposta, a injustiça ultrapassa todos os parâmetros anteriormente considerados. O temor de Arendt é que essa nova instituição pairasse como um espectro exemplar e se constituísse como parte essencial da vida contemporânea. Arendt é enfática em Origens do Totalitarismo: estamos diante de uma nova forma de governo. Talvez por isso ela tenha afirmado que "os verdadeiros transes do nosso tempo somente venham a assumir a sua forma autêntica - embora não necessariamente a mais cruel - quando o totalitarismo pertencer ao passado"1. Havia, na filósofa, a percepção do perigo de que o crime, o extermínio, a nova terapia contra os humanos considerados impuros e indignos, com os governos totalitários, tenha se constituído em elemento imanente aos governos e sociedades contemporâneas. Esse era o grande temor presente nos textos de Hannah Arendt. Se a dominação total explicita sua propensão exterminadora nos campos de concentração que lhe dão sustentação, a tendência à morte e à eliminação de humanos passa a ser visível em formas sociais nas quais não há explicitamente os campos de extermínio. A propensão totalitária se incrusta de maneira essencial nas exceções ou exclusões cotidianas que se fazem presentes na violência contra trabalhadores, imigrantes, índios, presidiários, crianças, velhos, jovens, apátridas, nas favelas, nas guerras, na fome, nas doenças, nas formas de controlar a longevidade e natalidades de setores da população, nos presídios, na tentativa de dominar e controlar geneticamente a reprodução de homens. Nesses setores da população, aos poucos, o princípio da homogeneização, da purificação e exterminação vai se realizando sem que tomemos consciência, sem que debatamos sobre o assunto. Foi essa injustiça profunda que Arendt percebeu e por essa razão sua reflexão ultrapassou a circunscrição da questão judaica e passou a dizer respeito a todos nós.

Embora Arendt não tenhlha realizado uma discussão sistemática com a tradição filosófica, é no contexto da discussão sobre o mal que iremos inserir o tema da injustiça nessa autora. Jerome Kohn, assistente de ensino e intérprete de Arendt, chega a dizer que o problema do mal constitui-se no principal eixo argumentativo que atravessa toda a reflexão político-filosófica arendtiana. ${ }^{2}$ Assim como o mal é um desafio para a Filosofia, o paroxismo da injustiça e da violência nas atuais sociedades apresenta-se como um "desafio ao pensamento". A relação entre injustiça e mal mostra-se como uma perspectiva heuristicamente produtiva na medida em que mantém essa dimensão do

${ }^{1}$ ARENDT, H. Origens do Totalitarismo. Tradução de Roberto Raposo. São Paulo: Companhia das Letras, 1990, p. 512 .

${ }^{2}$ Cf. KOHN, Jerome. "O mal e a pluralidade: o caminho de Hannah Arendt em direção À Vida do Espirito". In Origens do Totalitarismo: 50 anos depois. Tradução de Odilio Alves Aguiar. Rio de Janeiro: Relume-Dumará, 2001, p. 32 , 
inalcançável, assintótica, "misteriosa e indizível" que perpassa as situações humanas limítrofes. Trata-se de reconhecer a dimensão de fronteira embutida em fenômenos que apontam o mal como a categoria capaz de iluminá-los ${ }^{3}$. Vale dizer, esses fenômenos não são explicáveis apenas por uma área ou setor do saber humano, uma vez que exige um trabalho de compreensão que ultrapassa as visões compartimentalizadas próprias às ciências contemporâneas.

Essa discussão em Arendt, no entanto, não é fruto de mero exercício de erudição. Hannah Arendt nasceu na Alemanha em 1906. De origem judaica, teve que abandonar a Pátria alemã em virtude da ascensão dos nazistas. Refugiou-se na França e depois nos Estados Unidos, onde adquiriu cidadania. Na América, em 1943, perplexa, toma conhecimento de Auschwitz, da matança sistemática dos judeus e outros setores da população alemã nas câmaras de gás dos campos de concentração. A partir de então, resolve concentrar-se intelectualmente na compreensão desse fenômeno que, segundo ela, desafiava todas as categorias e teorias produzidas no Ocidente. Fruto dessa empreita, surge, em 1951, o livro Origens do Totalitarismo. É justamente no contexto da tentativa de compreender a novidade da forma totalitária de governar que Arendt vai usar a expressão kantiana do mal radical. Para ela, "(...) nossa tradição não pode conceber um "mal radical" como também a teologia cristã que concedeu ao diabo uma origem celestial. Somente Kant, o único filósofo que, pela denominação que lhe deu, ao menos deve ter suspeitado de que esse mal existia..." 4 .

$\mathrm{Na}$ trillha aberta por Kant, Arendt, ao recorrer ao mal radical, indica uma possibilidade de pensá-lo para além da visão da Metafísica e da Teodiceia, isto é, o mal como não-ser e para além da visão moral, como deliberação pela maldade, presente nos vícios humanos.

Relacionar a injustiça ao mal, não favorece de todo o nosso trabalho compreensivo, uma vez que a tendência tradicional, inclusive na Filosofia, é encarar o problema do mal na perspectiva da Metafísica ou da Teodiceia, cujo otimismo não permite pensar a positividade do mal e a injustiça na sua radicalidade. A tradição filosófica rejeitou a positividade do mal porque implicava o reconhecimento do mal como ser, possuidor de densidade ontológica. A malignidade do mal, o princípio do mal, assim, seria entificada ou personificada num ser maligno (o homem ou diabo). Essa positivação levaria a uma concepção da maldade como inerente ao ser humano, não como possibilidade e sim determinação. ${ }^{5}$

Dentro desse espectro, tentaremos conduzir o nosso argumento de tal forma que seja possível pensar a positividade do mal sem, no entanto, recorrer ao conceito de malignidade do mal. Com isso, encaramos o desafio de pensar o mal no contexto das formas de sociabilidade secularizadas. Vale dizer, a categoria do mal, na nossa compreensão, só tem valor heurístico, hoje, se for pensada para além da perspectiva moral e religiosa. É insuficiente abordar o mal como uma questão de pecado, bem como mera transgressão moral. Ações motivadas pela inveja, ambição, ódio ou outros sentimentos do tipo são incapazes de justificar o recrudescimento da injustiça e da violência no mundo hodierno. Situar, assim, o problema, é importante porque facilita a compreensão da incapacidade da sanção religiosa ou moral vigorar nos dias atuais. A perda da evidência dos valores morais e religiosos inviabiliza esse caminho. Verifica-se, hoje, uma ruptura com a tradição moral e religiosa que antes vigorava como elemento legitimador da vida em comum.

${ }^{3}$ LIBÂNIO, João Batista, "O Mal: Problema de Fronteira". In CIRNE-LIMA, Carlos e ALMEIDA, Custódio (Orgs.) Nós e o Absoluto, p. 219-235 e RICOEUR, Paul. O mal. Um desafio à filosofia è teologia. Campinas: Papirus, 1988 .

${ }^{4}$ ARENDT, H. Origens do Totalitarismo. Tradução de Roberto Raposo. São Paulo: Companhia das Letras, 1990, p. 510 .

${ }^{5}$ O otimismo da tradição conviveu com perspectivas que de alguma forma enfatizaram a dimensão ou propensão do homem para o mal. O homem, nessa visão, não é apenas um ser para o amor e a vida, mas, também, para a morte, egoísmo e o ódio. Basta pensar na assertiva hobbesiana do homo homini lupus ou a pulsão de morte em Freud. A tendência ao gozo propende a coisificar e anular o homem. Cf. GARCIA-ROZA.O Mal Radical em Freud. Rio de Janeiro: Jorge Zahar, 1999. 
Conceituar o mal não é fácil. Os gregos inauguraram a pergunta pela origem do mal (Pothen to kakon). A indagação já foi feita dentro em um contexto de questionamento das respostas mitológicas que trabalhavam com a compreensão de destino inelutável. A resposta metafísica a essa questão deu o tom da visão que perdurou na tradição. Nessa perspectiva, o mal estaria relacionado ao mundo sensível, à dimensão animal, passional do homem. Haveria uma conexão entre o mal e a matéria, ao campo da sensibilidade. O mal, desse modo, não teria estatuto ontológico, seria pensado como privação, imperfeição, defeito. O mal é pensado como os buracos no queijo. A falta implicaria o vazio do ser a partir de onde poderia germinar o mal. Quanto mais os homens pendessem para a escala baixa dos seres, mais próximos da matéria, mais propensos estariam para a maldade. A renúncia da dimensão espiritual levaria os seres inteligentes a se tornarem vulneráveis ao mal. Desse modo, o mal estaria relacionado à degradação dos seres inteligentes e o bem à ascensão desses seres em direção à sua natureza espiritual.

Um avanço na tematização do problema do $\mathrm{mal}$, pode ser verificado em Santo Agostinho. O autor combina o horizonte metafísico com a Teodiceia, que nasce da tentativa de resolver a contradição entre a bondade e perfeição de Deus e a existência do mal. O princípio lógico da não-contradição diz que dois predicados opostos não podem pertencer ao mesmo sujeito. Como, então, o Criador, um ser perfeito, permitiu o aparecimento do mal, a imperfeição? Mais do que isso: como compreender o mal imerecido, o sofrimento dos inocentes, as doenças? Da Metafísica, Agostinho retira a compreensão do mal como falta, privação do bem. O mal não é ontológico, não possui ser. Ele emerge a partir do exercício da escolha humana. Em De Liberum Arbitrium, Agostinho identifica uma iniância ${ }^{6}$, uma impulsividade sensitiva no homem, marca do mal metafísico nos seres criados, que funciona como um lugar da degradação humana. Escolher esse lugar (mundano, das ilusões, das paixões) é distanciar-se do lugar próprio, da essência espiritual, imagem e semelhança de Deus para a qual o homem fora criado. Haveria, nesse caso, o predomínio da matéria sobre o espírito, dos sentidos sobre a transcendência. O homem foi criado dentro de uma escala dentro da qual quanto mais perto da dimensão espiritual, mais próximo do bem e, quanto mais unido à matéria, mais vizinho do mal. O mal não seria, assim, ontológico, mas moral, enraizado nas opções pelas coisas mundanas.

Na perspectiva da Teodiceia, prevalece o otimismo. O sofrimento, a dor, as doenças e os cataclismos naturais são pensados em vista do triunfo do bem. Provavelmente nasceu aí a nossa tendência a sempre ver sentido nas ações más, pois elas levarão e realçarão a vitória do bem. Somente assim pode-se entender o mal imerecido, as vítimas inocentes. Através dessas vítimas, a espécie humana vai se purificando. Esse é o esquema mental que justifica possíveis ações más em nome do bem, algo como "dos males o menor" ou como "em nome do bem-estar de todos é razoável o sacrifício de alguns" e "em nome da civilização e da liberdade é justo eliminar os bárbaros" e por aí vai. Até mesmo o argumento do progresso aproveitou-se do esquema de pensamento da Teodiceia, do entendimento de que vivemos no melhor dos mundos possíveis. No fim, tudo vai dar certo: o homem vai ser livre e viverá na abundância.

Schelling, no seu texto sobre A Essência da Liberdade Humana (1990), identifica liberdade e razão, iniciando, assim, uma linhha de raciocínio que será acolhida no idealismo alemão, principalmente por Kant, em A Religião nos Limites da Simples Razão. ${ }^{7}$ Contrariamente à tradição metafísica, o mal não será relacionado à matéria, às

\footnotetext{
${ }^{6}$ O termo iniância é mantido por alguns tradutores de Agostinho, como, por exemplo, Antônio Soares Pinheiro. Outros preferem concupiscência ou libido. Preferimos iniância porque não acentua o teor sexual que as outras traduções carregam e aponta mais para a fenda proveniente da incompletude inerente aos seres criados, finitos e à tentativa de preenchimento com as coisas materiais, sensíveis.

${ }^{7}$ Essa perspectiva se faz fortemente presente na análise hegeliana da Revolução Francesa. Essa revolução é concebida como manifestação do espírito absoluto no mundo, figura da razão, evento que simbolizaria a efetivação da liberdade no mundo. Mas a revolução resvalou para a violência nua e crua com o terror jacobino, também percebido por Hegel. Assim o que era realização máxima da liberdade passa a dar lugar à realização
} 
paixões, aos sentidos. O mal passará a se inscrever no interior mesmo da liberdade humana, como algo enraizado na mais alta capacidade espiritual dos homens: a razão. Na capacidade humana para a liberdade, emerge a potência para a positivação do mal: o mal radical. Esse mal foi considerado radical porque ele não é explicável a partir da maldade. De alguma forma, ele nasce e atinge a essência mesmo do homem: a liberdade espiritual. O mal, assim, é positividade na medida em que implica resistência consciente ao bem. Essa tematização segue uma linha de raciocínio também presente, de alguma forma, em Kant, associada, desta feita à instrumentalização do homem, ao uso do homem como meio e não como fim em si mesmo. Daí sua radicalidade. O mal radical implica a destruição mesmo da humanidade do homem. É essa humanidade presente em qualquer ser humano que o mal radical, kantianamente falando, quer ver destruída. Além desse aspecto, a raiz do mal em Kant será relacionado ao amor-próprio que impulsionará os homens a transgredir as leis morais. Isto é, o mal radical liga-se a uma predisposição natural do homem a inclinar-se e a ceder às suas apetições. Apesar disso, há em Kant resquício de Teodiceia e, no limite, ele acredita que vai prevalecer, do ponto de vista objetivo, a lei moral universal, o bem.

Na trilha aberta por Kant, Arendt, ao recorrer ao mal radical, torna possível pensar a injustiça na sua radicalidade, o mal na sula positividade, sem, no entanto, aceitar a malignidade do mal, sem precisar recorrer à noção de um ser maligno. Arendt identifica como a positivação do mal no mundo, a tentativa de instituir um governo com pretensão de domínio total, baseado nos campos de concentração. ${ }^{8}$ Desta feita, o mal radical é uma categoria que ultrapassa a dimensão moral e teológica, âmbito no qual o mal vinha sendo pensado e adquire um estatuto político?

Ao usar a teoria de mal radical para compreender o totalitarismo, Arendt enseja captar a especificidade de uma forma de sociabilidade totalmente nova. O novo, no caso, não é a intensidade da violência, o uso dos instrumentos e armas bélicas, mas a tentativa primeira de construir uma organização comunitária abandonando a política, a forma típica das organizações comunitárias no Ocidente, e legitimada pela morte, a dor e a solidão. A nova forma enseja constituir-se não a partir dos contatos humanos, mas da solidão e do desamparo dos indivíduos inseridos nos grupos humanos massificados. 0 medo, a inimizade, na forma do inimigo objetivo, são os "princípios" ordenadores dessa nova forma de governo. Daí a novidade desse novo regime de governo, pois, segundo Arendtt, não há na Filosofia Política nenhuma teoria de governo capaz de dar conta dessa novidade ${ }^{10}$. Nem mesmo as teorias sobre os governos tirânicos são apropriadas para se pensar as formas de governo baseadas no terror totalitário.

A pretensão de domínio total é o núcleo a partir de onde se pode pensar o mal radical das experiências totalitárias. Os "campos de concentração" representam o emblema maior desse tịpo de governo. Eles são a exceção, o espaço excepcional que funciona como o núcleo essencial e paradigma do sistema. Como órgão encarregado de

do mal. O terror, a destruição e o medo são, assim, uma possibilidade inscrita no âmago das mais altas capacidades humanas para a liberdade.

${ }^{8}$ Esse aspecto do mal, em Hannah Arendt, está muito bem abordado por Nádia Souki em Hannah Arendt e a Banalidade do Mal, Belo Horizonte: Ed. UFMG, 1998, p. 36-37. Esse livro, ademais, constitui excelente subsídio a quem se interessar sobre esse tema em Arendt. Essa dimensão política do mal radical também está presente no texto referido de Ricouer. Para o autor, o mal radical tem origem nas pretensões de realização e totalização inerentes à razão pura e prática. A perversão desse desejo deu origem ao totalitarismo. Para Ricouer, o verdadeiro mal radical aparece através do Estado e da Religião, instituições de reunião, de recapitulação, de totalização. A relação entre mal radical e política, totalitarismo e razão está, também, muito bem argumentada no livro Do Mal, de Denis Rosenfield.

${ }^{9}$ Paul Ricouer, em Introduccion a la simbólica del mal, Buenos Aires: Megapólis, 1976 p. 164 , argumenta que "O verdadeiro, o mal do mal, se mostra com as falsas sínteses, isto é, com as falsificações contemporâneas das grandes empresas de totalização da experiências cultural, nas instituições políticas e eclesiásticas. Е́, então, que o mal mostra seu verdadeiro rosto, o mal do mal sendo a mentira das súnteses prematuras, das totalizações violentas."

10 Cf, a respeito STANLEY, John L. Is totalitarianism a new phenomenon? Reflections on Hannah Arendt's Origins of totalitarianism. In: HINCHMAN, Lewis et Sandra, HINCHMAN (Org.).Hannah Arendt critical essays. New York: State University of New York Press, 1994. p. 7-40. 
fabricar sistematicamente cadáveres, os campos de concentração tornaram-se o símbolo do mal radical. A eficácia ou legitimação de um governo ou qualquer outra instituição com pretensão de domínio total só pode se dá na medida em que os homens são eliminados como seres humanos. No máximo, serão admitidos "mortos-vivos", seres humanos reduzidos à sua dimensão animal, sem poder interagir, falar, pensar e agir livre e espontaneamente. Evidentemente essa animalidade não seria natural, mas artificialmente fabricada. ${ }^{11}$ Por isso, o governo totalitário é uma forma de governo cuja condição de sustentação pressupõe a descartabilidade dos homens, visa eliminar a finitude e a diversidade humana. Esses elementos fazem com que surja, pela primeira vez, uma forma política na qual a propensão a eliminar a humanidade do homem ganha positividade e, por essa razão, Arendt irá relacioná-la ao mal radical.

A injustiça radical inerente às formas totalitárias de governar conduzem Arendt, noutro momento, a elaborar a noção de banalidade do mal. Essa expressão em Arendt tem densidade filosófica. Arendt não está dizendo que o mal é algo que pode ser tomado como banal. Ao contrário, ela quer justamente chamar atenção para as formas contemporâneas do espraiamento do mal. Arendt usou essa dicção após presenciar o julgamento de Eichmann em Jerusalém, em 1961. Eichmann foi membro do governo nazista e era encarregado de enviar judeus para os campos de concentração. Em todos os relatos de Arendt, verificamos uma profunda perplexidade pela forma como Eichmann falava das suas atividades como carrasco nazista. Eichmann usava clichês, palavras de ordens e a moral da obrigação do bom funcionário para justificar a sua atividade. Essa atividade, para ele, em nenhum momento podia ser enquadrada como criminosa, pois apenas cumpria a sua obrigação, o seu dever. Eichmann era um ser humano normal. Dizia que não possuía nenhum ódio ao povo judeu, ao contrário, o judeu, como o alemão, era para ele um povo idealista, pois não se contentava com a pequenez do modo de vida pequeno-burguês, fundado no ỉnteresse econômico. Arendt verifica que Eichmannn não era motivado por uma vontade de transgredir ou por qualquer tipo de maldade. Não há uma vontade má em Eichmanin e, no entanto, ele viabilizou o assassinato de milhões de pessoas. É justamente isso que levou Arendt a usar o termo banalidade do mal. O mal, nesse caso, é perpetrado por seres humanos que resistem ao pensamento, presos às pressões cotidianas da função e, identificados com a pertença a um grupo, raça, nação ou partido, rejeitam julgar o que fazem e a pensar no que está acontecendo ao seu redor. ${ }^{12}$ Para Arendt, a prática do mal que pode ser chamada de banal não é fruto de deliberação. Não há uma escolha, não há o exercício do livre-arbítrio, nem se verifica aí uma atividade da consciência e, sim, o cancelamento dessa atividade. Ao mal banal, Arendt associa o "vazio de pensamento" (thougthlessness) e de julgamento. $O$ agente do mal banal age como o cão de Pavlov: manipulado, condicionado, disciplinado, bitolado.

Ao relacionar o mal ao vazio de pensamento, Arendt aponta para uma possível compreensão do mal e da injustiça nas sociedades contemporâneas. Nessas sociedades, o mal realiza-se na forma da banalidade do mal. A injustiça entifica-se na violência radical propiciadora de práticas banais de violência, extermínio e extinção de seres humanos. Estamos diante de um tipo de mal para o qual não é possível relacionar a maldade, patologia ou convicção. Trata-se do mal como causa do mal, pois não tem outro fundamento. O praticante do mal banal não conhece a culpa. Ele age como uma engrenagem maquínica do mal. O mal banal é típico das sociedades onde reinam o anonimato, a propaganda e a massificação. Esse é um campo fértil para o mal nascer como um fungo, com capacidade de crescer e se espalhar como causa de si mesmo, sem

\footnotetext{
11 Sobre isso, cf. especialmente os capítulos "Dominação Total" e "Ideologia e Terror", in Origens do Totalitarismo de Hannah Arendt e, também, de CHAUMONT, J.-M. La singularité de l'univers concentrationaire selon Hannah Arendt. In: ROVIELLO, A.-M; WEIYEMBERGH, M. (Org.). Hamnah Arendt et la modernité. Paris: Vrin, 1992, p. 87-110.

${ }^{12}$ Cf. CHALIER, Catherine. Radicalité et banalité du Mal. In: ABENSOUR, Miguel (Ed.). Ontologie et́ politique. Paris: Tierce, 1989, p. 237-256; LANG, Berel. Hannah Arendt and the Politics of Evil. In: Hannah Arendt and the politics of evil. Ed. Lewis P. Hinchman e Sandra Hinchman. New York: State University of New York Press, $1994,41-55$
} 
raiz alguma e, ao mesmo tempo, atingir contingentes enormes das populações humanas em diversos lugares da terra. O praticante do mal banal age como um ninguém, exemplar mudo de um grupo. Eichmann, segundo Arendt, agiu como o cão de Pavlov, que foi condicionado a salivar mesmo sem ter fome. Eichmann renunciou à capacidade humana de julgar e de pensar e, ao fazê-lo, agiu como se fosse condicionado. Eichmann não praticou o mal motivado pela ambição, ódio ou por uma escolha proveniente da determinação sensível que pudéssemos igualá-lo a um animal. Nada disso encontramos em Eichmann. Ao contrário, foi justamente a renúncia à capacidade de escollher e de julgar que fez Eichmann agir como mera correia de transmissão de uma lógica assassina sistemática. Ao renunciar ao julgamento, Eichmann destituiu-se da condição de ser dotado de psiquê que lhe possibilitaria o descondicionamento e, assim, dizer: não, isso eu "não posso".

Os "crimes contra a humanidade", rotineiros no mundo contemporâneo, sinalizam a possibilidade do prevalecimento da injustiça radical, do mal e da violência. Com o surgimento da banalidade do mal, passamos a ter no nosso horizonte fático um tipo de mal cuja prática direciona-se contra a humanidade mesma, não como abstração, mas na sua diversidade fenomenológica. É a humanidade como tal que o mal banal atinge. O mal banal é feito em contraposição à condição huumana, uma vez que nele há a rejeição da diversidade humana e a tentativa de determinar que homem pode habitar a terra. Na prática do mal banal, está em jogo a atitude de homens que não querem dividir a terra com os outros (imigrantes, apátridas, índios, favelados, vellhos, crianças, doentes, pobres etc).

A compreensão de mal radical e banal, em Arendt, ultrapassam, assim, as tradicionais experiências de injustiça: a exploração econômica, o preconceito social, a exclusão política. Em todas essas situações, de alguma forma, permanece intacta e respeitada a vida do homem enquanto homem: o escravo, o pobre, o banido político mantém sua vida, há algum "olhar protetor" lançados a eles, assim como conseguem manter a capacidade de mudar as coisas. Sob a vigência da injustiça radical, não há nenhum direito, nenhum vínculo, nenhuma forma de organização. Todas as formas de vida propriamente humana ficam interditadas. É o desamparo, a solidão, o isolamento e a morte. Vigora o coletivismo biológico, animal, nivelador, mudo, padronizado e somente como ser biológico, burocrático, passivo, indiferente, funcional é que a vida ainda consegue ser vivida, antes da decretação da sua total extinção.

Contra essa injustiça radical, emerge, em Arendt, a compreensão de justiça como julgamento. Com essa ideia, temos o distanciamento, nessa autora, dos conceitos tradicionais da justiça como virtude e como valor. Esse aspecto foi muito bem desenvolvido por Christina Ribas, no seu livro A justiça no pensamento de Hannah Arendt (2005). A justiça como julgamento é o outro lado da visão da política como resistência em Arendt.

A concepção clássica entende a justiça como virtude e a virtude como a realização apropriada da função de cada um na ordem cósmica e política. O desempenho virtuoso, harmonioso da função na cidade é a garantia de que se está de acordo com a teleologia específica. A contraposição a essa concepção de virtude reside no excesso. 0 excesso é marca do vício. Ser justo é agir dentro dos limites da lei e da virtude. O vício coloca em perigo a harmonia da cidade e a realização da natureza humana do homem. $O$ problema, apontado por Arendt, nessa concepção de justiça como virtude, é que nela os fins são dados pela teleologia natural ou pela comunidade. Virtude é tudo que engrandece e fortalece a Polis. As virtudes consistem em agir dentro desses parâmetros dados pela natureza e pela cidade. Após Auschwitz, forma extremada do racismo de Estado e da constituição, pela primeira vez na história da humanidade, de um Estado totalitário e criminoso, não dá mais para confiar nos valores da cidade, no consenso estabelecido. Nesse caso, a homonoia, o consenso júris (a confiança na concórdia diante das discórdias), dos gregos e romanos, foram destruídas pela ideia de inimigo objetivo, ideologicamente determinado. Trata-se da pessoa que não é opositor ao regime nem cometeu algum crime; contra ele não há nenhuma culpa juridicamente imputada, muito 
menos ofensa presumível. Incriminam-se, assim, as pessoas partindo do pressuposto de serem elas, pela pertença nacional, grupal ou biológica, capazes de um crime possível, logicamente previsível. Da mesma forma, com o surgimento do mal radical e banal, o conceito de vício é insuficiente para captar a injustiça radical e banal. A raiz desses males não está nos vícios humanos ou na maldade. Numa situação de vigência das leis num sistema de governo totalitário, a obediência a lei ao invés de indicar a prática da virtude, indica a conivência com o crime e a morte.

Da mesma forma, a concepção da justiça como valor mostra-se insuficiente para evitar o mal banal. Essa visão do valor é tipicamente moderna e, poderíamos dizer, na trilha de Arendt, que ela tem como pano de fundo o triunfo do animal laborans e do homo faber, isto é, a perda da experiência da justiça como virtude e a ascensão do valortrabalho como paradigma. Na compreensão moderna de valor, não há uma finalidade última, como a virtude e a felicidade para os antigos, mas a aceitação de que a justiça se restringe ao conjunto das normas vigentes e aceitas pela população de um Estado. Não há questionamento da norma vigente, pois entende-se que sua aceitação é a única condição de possibilidade de efetivação mínima da justiça. Ocorre que, da mesma forma como mudam os padrões da produção e da velocidade da circulação dos objetos na sociedade do consumo, eminentemente laborista, cujo critério de realização e felicidade é medido pela posse de objetos, nessa mesma velocidade mudam as normas, produzem-se leis. As normas legais dissociam-se completamente do estabelecimento da vida em comum e, no melhor dos casos, geram apenas a uniformização social. Da mesma forma como o valor-trabalho dissociou-se do valor de uso e rendeu-se à lógica especulativa das coisas transformadas em mercadorias, dominadas pelo valor do mercado capitalista, também a norma jurídica, parâmetro da justiça no mundo moderno, cinde-se de qualquer outra finalidade, como por exemplo, a felicidade pública, a vida comum, a virtude, etc. Na situação moderna, um valor pode ser substituído por outro de acordo com os fins a serem atingidos. Assim, muda-se radicalmente de valores dependendo da finalidade estabelecida. Perdemos a noção de valia, de valor intrínseco e passamos a ver tudo a partir do critério do mercado ou do contexto social. Foi isso que Arendt percebeu nitidamente no regime nazista. Em momento algum a Constituição de Weimar, democraticamente elaborada, foi revogada, mas produziu-se normas e mais normas que efetivamente passaram a regular de forma racista a vida alemã.

Desse modo, com a ruptura nazista mostraram-se insuficientes tanto a concepção clássica da justiça-virtude quanto a ideia moderna da justiça-valor. Punha-se a questão: como fazer justiça quando nenhuma norma ou lei são suficientes para enquadrar um crime completamente novo, inexistente na prática e nos códigos jurídicos, como foi o caso do genocídio? Estamos diante de uma situação na qual nem a lei natural nem a lei formal tinham qualquer utilidade, no entanto, o senso de justiça exige que se faça justiça, pois tinha-se o crime, mas não se tînha a regra, a lei, a norma. Qual o procedimento apropriado para julgar na ausência da regra geral? a qual regra subsumir o caso concreto? Tratava-se de julgar no desamparo da regra geral específica. O que estava em questão era pensar a resistência ao espraiamento do mal. Daí a razão do pensar e julgar funcionar, para Arendt, à maneira de um último recurso afirmador da humanidade dos homens em situações de "desbussolamento" generalizado, próprias aos "tempos sombrios", em seus vários momentos experimentados na história humana, mas principalmente na contemporaneidade. ${ }^{13}$ Numa situação como essa, a justiça só tem uma possibilidade de realização: a ativação da capacidade humana de julgar. "Justiça é uma questão de julgamento", diz Arendt. ${ }^{14}$ Isto é, a justiça não tem essência fora da existência humana e uma vez que se trata de julgar ações humanas, estamos diante de realidades que não são determinadas pela natureza, pois no mundo humano o que aconteceu.

${ }^{13}$ Sobre o julgar, cf. em especial, de Arendi, Lições sobre a Filosofia Polfica de Kant Trad. de André Duarte de Macedo. Rio de Janeiro: Relume-Dumará, 1993; e Responsabilidade e Julgamento. Tradução de Rosaura Einchenberg. São Paulo: Companhia das Letras, 2004.

${ }^{14}$ Cf. Eichmann em Jerusalén: um relato sobre a banalidade do mal. Tradução de José Rubens Siqueira. São Paulo: Companhia das Letras, 2000, p. 320. 
poderia não ter acontecido. Nenhum determinismo, nenhum processo pode justificar a negação da faculdade de julgar e a responsabilidade a ela inerente. Não se trata de julgar pessoas, de alfinetar suas consciências, pois no julgamento o que está em questão é o mundo. Se o juízo não for exercido, o mal se espalhará e a injustiça triunfará.

Julgar não é raciocinar, mas em primeiro lugar partillhar o mundo. Não se trata de uma operação lógica, mas da capacidade e da sensibilidade humana para lidar com o que está acontecendo no mundo público. Arendt pensou o julgamento no modelo proposto por Kant na terceira crítica. Kant pensa dois tipos de juízos: o determinante, no qual o particular é enquadrado numa legalidade universal aceita como tal. 0 juízo determinante é próprio à ciência e à moral. Nesses setores, o critério universal é dado. Por outro lado, temos o juízo reflexionante ou indeterminado no qual somente o particular é dado e não existe nenlhuma lei universal a ser aplicada. Segundo Kant, esse é - caso do juízo estético e que Arendt acha apropriado para o juízo político na contemporaneidade, em razão da prevalência do amorfismo ético-político-jurídico. Numa situação como essa, julgar é escolher e o único apoio que pode acudir o homem é o pensamento, o diálogo interno e o bom senso, o sensus comunnis, a certeza de que o mundo é habitado por outras pessoas que poderão entender e partilhar o seu julgamento. O julgamento vai permitir orientar-se no mundo comum numa situação de desbussolamento generalizado. Mas "quem sou eu para julgar?" Um cidadão que deve impedir que se faça o mal, pois está em jogo o mundo compartilhado por todos.

Julgar, mostra-se, assim, como um equivalente à capacidade política de iniciar, fundar, começar. Repõe a espontaneidade e a esperança que a funcionalização e a tentativa de controle total ambicionavam destruir. Para Arendt, o julgamento está, também, ligado à capacidade humana de falar, de buscar e de atribuir sentido. A busca da significação encontra muita dificuldade quando a pressa, os mecanismos e procedimentos técnicos, burocráticos e os processos econômicos autopropelidos engolfam tudo e passam, de certa forma, a proibir o levantamento da questão do sentido. Diante da mentalidade técnica e econômica vigente, julgar é uma forma de resistência que pode repor a potência humana, não como dominação, mas como retomada da possibilidade dos homens habitarem o mundo comum. Ao julgar, o homem ultrapassa a mudez e o isolamento que os padrões econômicos e sociais querem impor, e sinaliza que mesmo diante da mais destruidora injustiça, uma luz bruxuleante resiste a fim de sinalizar que os homens não nasceram para morrer, mas para começar.

\section{Referências}

ABENSOUR, Miguel. Hannah Arendt: o totalitarismo e a servidão voluntária. In: NOVAES, Adauto (Org.). A outra margem do Ocidente. São Paulo: Companhia das Letras, 1999.

AGOSTINHO, Santo. O Iivre-arbítrio. Trad. de Nair Assis Oliveira. São Paulo: Paulus, 1995. 1990.

. O livre-arbítrio. Trad. de Antônio Soares Pinheiro. Braga: Faculdade de Filosofia.

ARENDT, Hannah. Origens do totalitarismo. Tradução de Roberto Raposo. São Paulo: Companhia das Letras, 1990.

A condição humana. Tradução de Roberto Raposo e Adriano Correia. Rio de Janeiro: Forense, 2010.

Eichmann em Jerusalém: um relato sobre a banalidade do mal. Tradução de José Rubens Siqueira. São Paulo: Companhia das Letras, 2000.

Entre o passado e o futuro. Tradução Mauro Barbosa de Almeida. São Paulo: Perspectiva, 2000b. 
Lições sobre a Filosofia Política de Kant Trad. de André Duarte de Macedo. Rio de Janeiro: Relume-Dumará, 1993.

A vida do espírito. Tradução de Antônio Abranches et al. Rio de Janeiro: RelumeDumará, 1992.

Responsabilidade e Julgamento. Tradução de Rosaura Einchenberg. São Paulo: Companhia das Letras, 2004.

CHALIER, Catherine. Radicalité et banalité du Mal. In: ABENSOUR, Miguel (Ed.)。 Ontologie et politique. Paris: Tierce, 1989, p. 237-256.

CHAUMONT, J.-M. La singularité de l'univers concentrationaire selon Hannah Arendt. In: ROVIELLO, A.-M; WEIYEMBERGH, M. (Org.). Hannah Arendt et la modernité. Paris: Vrin, 1992, p. 87-110.

CIRNE-LIMA, Carlos et ALMEIDA, Custódio. Nós e o Absoluto. Rio de Janeiro, Loyola, 2001 .

GARCIA-ROSA. Luis Alfredo. O mal radical em Freud. Rio de Janeiro: Jorge Zahar, 1999.

KANT. I. A Religião dentro dos limites da simples razão. Tradução de Artur Morão. Covilhã: Luso filosofia Press, 2008.

KOHN, Jerome. O mal e a pluralidade: o caminho de Hannalh Arendt em direção À Vida do Espirito. In: AGUIAR, O. et Al. (Org.). Origens do Totalitarismo: 50 anos depois. Rio de Janeiro: Relume-Dumará, 2001, p. 9-36.

LANG, Berel. Hannah Arendt and the Politics of Evil. In: Hannah Arendt and the politics of evil. Ed. Lewis P. Hinchman e Sandra Hinchman. New York: State University of New York Press, 1994, 41-55.

RIBAS, Christina Miranda. Justiça em tempos sombrios. Ponta Grossa: Ed. UEPG, 2005.

RICOEUR. P. O mal. Um desafio à Filosofia e à Teologia. Campinas: Papirus, 1988.

Introdución a la simbólica del mal. Buenos Aires: Megapolis, 1976.

ROSENFIELD, Denis L。 Do mal. Porto Alegre: L\&PM, 1988.

SCHELLING, F. A essência da liberdade humana. Petrópolis: Vozes, 1990.

SOUKI, Nádia. Hannah Arendt e a banalidade do mal. Belo Horizonte: Ed. UFMG, 1998.

STANLEY, John L. Is totalitarianism a new phenomenon? Reflections on Hannah Arendt's origins of totalitarianism. In: HINCHMAN, Lewis et Sandra, HINCHMAN (Org.). Hannah Arendt critical essays. New York: State University of New York Press, 1994. p. 740.

Doutor em Filosofia (USP, 1998)

Professor do Departamento de Filosofia (UFC)

Professor do PPG Filosofia (UFC)

E-mail: odilio@uol.com.br 